To appear in: Religion, Gender and Sexuality in Everyday Life, edited by P. Nynäs and A.K.T. Yip. Farnham: Ashgate.

\title{
Coping with Religious and Cultural Homophobia: Emotion and Narratives of Identity Threat among British Muslim Gay Men
}

\author{
Rusi Jaspal, PhD \\ University of Nottingham
}

In Britain, the social, political and legal positions of individuals who identify as lesbian, gay or bisexual have improved, which has generally led to greater tolerance and acceptance at the social level. However, there is evidence that ethnic and religious minority non-heterosexual individuals can continue to face discrimination from within their ethnic and/ or religious communities (Yip 2007). For instance, representations of homosexuality within ethnic and religious minority communities in Britain can often be negative and stigmatising (Yip 2012), which may in turn result in decreased willingness to 'come out' (Jaspal and Siraj 2011), as well as psychological 'conflict' (Bhugra 1997). Given that their religious and cultural groups can prescriptively advocate heteronormativity and compulsory heterosexuality, nonheterosexual ethnic and religious minority individuals may opt to remain 'invisible' (Murray 1997). Collectively, these factors can have profoundly negative social and psychological outcomes for those affected. This chapter focuses upon the narratives of British Muslim gay men $^{1}$ (BMGM) of Pakistani descent, who may face homophobia from both their ethnic and religious ingroups (Jaspal 2012).

There is now a growing tradition of research into the interface of religion and sexuality among BMGM (Jaspal and Cinnirella 2010, 2012, Yip 2004a, 2004b). Our research has examined the socio-psychological implications of being Muslim and gay for the selfconcept, with a particular focus upon identity threat and coping. A principal contention within this body of work has been that religious and cultural homophobia seems to encourage the perception among BMGM that their religious and sexual identities are entirely incompatible. This may have negative social, psychological and emotional outcomes. The present chapter makes a contribution to existing research by elucidating how BMGM may cope with religious and cultural homophobia.

The chapter begins with an overview of identity process theory (Breakwell 1986), a socio-psychological theory of identity construction, threat and coping, and the conceptual inter-relations between religious/cultural homophobia, identity and emotion among BMGM. The methodological account is followed by a detailed discussion of the following empirical themes: (i) identity dissonance and feelings of shame and guilt; (ii) ingroup norms, God's

\footnotetext{
${ }^{1}$ It is acknowledged that some ethnic and religious minority non-heterosexual men reject the sexual category 'gay' due to its 'White' connotations (e.g. Carlson 1997). Our studies have always been presented as investigations of 'being gay, Muslim and Pakistani' and participants have endorsed the category 'gay' (rather than 'bisexual' or 'straight') for sexual self-definition. Therefore, the term 'British Muslim gay men' seems appropriate here.
} 
norms and the experience of fear; and (iii) managing interpersonal relations and anger. The chapter attempts to theorise the potential effects of homophobia for identity and how individuals cope with threatened identity. Furthermore, it addresses the role of emotion in meaning-making vis-à-vis religious and sexual identities and the phenomenological aspects of emotional experience when identity is threatened.

\section{Identity, threat and coping}

In seeking to explore the socio-psychological implications of self-identification as gay and of religious faith, we have drawn upon tenets of Breakwell's (1986) identity process theory (IPT) (Jaspal \& Cinnirella 2010, 2012; Jaspal \& Siraj 2011). IPT integrates identity construction, threat and coping, while synthesising the social and psychological levels of analysis. The theory proposes that the structure of identity should be conceptualised in terms of its content and value/affect dimensions and that this structure is regulated by two universal processes, namely (i) the assimilation-accommodation process and (ii) the evaluation process. The assimilation-accommodation process refers to the absorption of new information in the identity structure (e.g. 'I am gay') and to the adjustment which takes place in order for it to become part of the structure (e.g. 'I am gay so maybe I cannot be a Muslim'). The evaluation process confers meaning and value upon the contents of identity.

IPT outlines seven identity principles which define the desirable end-states for identity. These principles guide the aforementioned identity processes. It is argued that the individual needs to perceive appropriate levels of self-continuity across time (continuity); uniqueness and differentiation from relevant others (distinctiveness); competence and control over their lives and future (self-efficacy); feelings of personal worth (self-esteem); significance and purpose within their lives (meaning); belonging within social groups (belonging); and compatibility and coherence between elements of their identities (psychological coherence). There is evidence that many of these principles are vulnerable to threat among BMGM. Pervasive homophobia within their religious and cultural groups can make it difficult to derive feelings of self-esteem on the basis of their gay identity and a sense of belonging in relevant ingroups, for instance (Bhugra 1997, Jaspal and Cinnirella 2010).

IPT suggests that, when the individual is unable to perceive appropriate levels of salient identity principles, identity is threatened and the individual will engage in coping strategies to alleviate the threat. A coping strategy is defined as 'any activity, in thought or deed, which has as its goal the removal or modification of a threat to identity' (Breakwell 1986: 78). Some strategies function at the intrapsychic level, such as denial that one is actually gay, or re-conceptualisation of what it means to be gay. Others function at a social level, such as isolation of oneself from others, or social denial of homosexuality, that is, accepting that one is gay but refusing to acknowledge this publicly.

\section{Experiencing religious and cultural homophobia}

Homophobia is a contentious term which has been the object of much scholarly debate (Yip 2012). It has typically been defined as 'the dread of being in close quarters with homosexuals' (Weinberg 1972: 4), and has been expanded to include feelings of disgust, 
aversion, anger, anxiety and discomfort towards homosexuals (Hudson and Ricketts 1980). More recently, Herek (2004) has challenged the largely psychological, individualistic conceptualisation of homophobia and therefore advocated a more pluralist approach, encompassing the individual, socio-structural, cultural and ideological dimensions of homophobia. Accordingly, in this chapter, religious and cultural homophobia is broadly conceptualised as encompassing those ideas, norms and representations from one's religious and cultural ingroups, which actively undermine and stigmatise homosexuality and thereby render gay identity a socially and/ or psychologically de-valued component of the selfconcept. The perception among BMGM that their salient (i.e. religious, ethno-cultural) group memberships are homophobic may be psychologically damaging, inducing stress and negative general mental health outcomes (Rosario et al. 2002).

The mainstream Islamic stance on homosexuality seems to be fundamentally negative. Islam emphasises the complementarity and unity of the two sexes, with distinguishable gender roles associated with either one (Yip 2004b). Given that homosexuality can undermine this patriarchal social structure, Islamic ideology strictly opposes it (Duran 1993), and homophobia is said to be prevalent in Islamic societies (Siraj 2009). It is acknowledged that there is an emerging 'reverse discourse' concerning the Islamic position on homosexuality, with some scholars arguing that there is indeed scope for the theological accommodation of homosexuality (e.g. Hugle 2010, Jamal 2001). However, such theological accommodation is still in its infancy, given that 'there are at present limited efforts in Islamic theology which offer non-heterosexual Muslims resources to construct a reverse discourse' (Yip 2005: 50). Furthermore, religious identity has been described as 'core' among most British Muslims. For instance, in a survey study, 74\% of Muslims saw their religion as 'very important', while only $46 \%$ of Sikhs and $43 \%$ of Hindus did (Modood et al. 1997). Thus, the dominant Islamic stance on homosexuality may affect how BMGM themselves construct their gay identity.

Pakistani ethnic culture is closely entwined with Islam $^{2}$ (Haqqani 2004), but there are distinctive elements of Pakistani culture which may be characterised as homophobic. Anthropological studies have described the 'silencing' of homosexuality within Pakistani culture, due to the cultural processes of heteronormativity and compulsory heterosexuality (Khan 1997). Pakistani culture attaches importance to the concept of izzat (personal and cultural honour), which is strictly enforced (Shaw 2000). An essential tenet of maintaining familial izzat is the fulfilment of the cultural expectation of heterosexual marriage, which in many cases is arranged by the family (Yip 2004b). Any contravention of cultural norms concerning sexuality (e.g. being gay) can be regarded as a threat to the ethno-cultural group as a whole, potentially resulting in negative consequences ranging from ostracisation to psychological or physical abuse (Jaspal and Siraj 2011). Therefore, homosexuality may be seen as threatening for Pakistani culture, resulting in a cultural homophobia.

Empirical research has demonstrated the socio-psychological challenges faced by BMGM of Pakistani descent due to the perceived incompatibilities associated with being Muslim, Pakistani and gay (Yip 2004a). In an early study of 'coming out' among British

\footnotetext{
${ }^{2}$ Pakistan was established as a homeland for the large Muslim minority in British India. Between 95-98\% of Pakistanis are Muslims. Moreover, studies demonstrate the 'core-ness' and centrality of Muslim identity among British Pakistanis (Modood et al 1997).
} 
South Asian gay men, Bhugra (1997) found that most participants disclosed their gay identities to non-South Asians in the first instance. Moreover, he noted feelings of regret, self-deprecation and self-hatred among many of his participants, given the 'traumatic discrepancy' between being Asian and gay. Bhugra (1997: 556) located the problem in the Asian gay man's difficulty in constructing 'a coherent sense of self from the two identities he seeks to attain: Asian and gay'. This alludes to threats to psychological coherence. Similarly, in terms of the belonging principle, he has described individuals as having 'a foot in each culture, without feeling a complete sense of belonging in either' (p. 555). This elucidates how identity may be affected among BMGM.

\section{Homophobia and emotionality}

The management of Muslim and gay identities and the experience of homophobia from salient ingroups can expose BMGM to hyper-threats to identity, that is, threats to several principles at once (Jaspal 2012). For instance, perceived homophobia from one's religious and cultural ingroups can inhibit a positive self-conception on the basis of one's gay identity, jeopardising self-esteem, and it can induce the perception that being gay and Muslim are incompatible and contradictory, potentially threatening the psychological coherence principle. However, there is no existing knowledge concerning the emotional consequences of this atypical identity configuration or concerning the experience of religious and cultural homophobia. Emotion constitutes an important area of investigation because it can influence perceptions, shape memories, contribute to the development of interpersonal relations and regulate behaviour (Massey 2002).

Emotion can be conceptualised in terms of 'a reaction to personally significant events, where "reaction" is taken to include biological, cognitive and behavioural reactions, as well as subjective feelings of pleasure or displeasure' (Parrott 2004: 6). Markus and Kitayama (1991) have proposed a conceptual dichotomy of emotions, whereby 'ego-focused' emotions (e.g. anger, frustration and pride) are experienced by independent and autonomous individuals, while 'other-focused' emotions (e.g. shame and sympathy) are generally experienced by interdependent, collectivistic individuals. Both the intrapsychic level of cognition (e.g. thinking about the compatibility of being Muslim and gay) and the social level of human interdependence (e.g. thinking about whether other Muslims will accept their gay identity) are important (Jaspal 2012). Thus, it is necessary to explore both ego-focused and other-focused emotions among BMGM.

Previous research into BMGM suggests that the emotions of shame, guilt, anger and fear can be stimulated by experiences of discrimination and homophobia from their religious and ethnic groups (Jaspal and Cinnirella 2010, Yip 2004a). Shame is the emotional response to perceived inadequacy of oneself and to potential self-exposure to disapproval from others (Broucek 1991). The cultural representation among many Pakistanis that being gay is 'immoral' may induce the emotion of shame, for instance. Guilt focuses on one's perceived wrongdoing and is more associated with one's private conscience than the risk of public exposure (Tangney and Fischer 1995). To that extent, shame is more 'social' than guilt. Anger usually arises when one interprets another's actions as a deliberate and unjustified transgression of normative standards (Averill 1982). For instance, Jaspal and Cinnirella 
(2012) have found that some BMGM may exhibit anger at the perpetrators of forced marriage, which may be regarded as an unjustified contravention of 'British standards'. Fear is an emotional response to a perceived risk of threat or danger (Öhman 2000). BMGM may perceive a risk of physical abuse from their homophobic ethnic and religious communities, for instance. Given that these emotions are invariably negative experiences for human beings, their arousal may induce defensive coping behaviours (Turner 1999), such as those described in IPT.

Emotional experience needs to be investigated in terms of its social and psychological dimensions. It is acknowledged that human culture impacts emotional experience by influencing the ways in which a given situation or stimulus will be evaluated and thus responded to emotionally (Harré and Finlay-Jones 1986). Furthermore, individuals' reflective narratives are always imbued with emotional experience (Eatough and Smith 2006), which highlights the feasibility and necessity of exploring emotion from the socio-psychological perspective of the individual. This chapter provides such a perspective among BMGM.

\section{Methodological account}

\section{The study}

The data presented in this chapter are drawn from four exploratory, qualitative interview studies conducted between 2008 and 2011. Collectively, these socio-psychological studies have explored various issues concerning the management of religious, ethnic and sexual identities (Jaspal 2012, Jaspal and Cinnirella 2010), interpersonal relations (Jaspal and Cinnirella 2012) and perceptions of 'coming out' among BMGM (Jaspal and Siraj 2011).

This work is characterised by (i) a psychological focus upon how BMGM perceive and cognitively manage their identities; (ii) a sociological concern with the development of relationships with other gay men of similar and different ethno-religious backgrounds; and (iii) a social focus upon the management of relationships with ethno-religious ingroup members. More generally, our approach acknowledges the reciprocal relationship between the intrapsychic level of cognition and the social contexts in which individual cognition is embedded.

This chapter is concerned with participants' responses to religious and cultural homophobia with identity threat and emotion as central foci. Throughout our interview studies, participants have manifested potent emotions and reflected upon their emotional experiences when thinking about the socio-psychological implications of being Muslim and gay. This chapter builds upon existing work on BMGM by providing preliminary insights into the general tendencies regarding threat and emotion, which are observable in our studies.

\section{Participants}

It is typically very difficult to obtain a representative sample of hidden populations such as BMGM (Heaphy et al. 1998), particularly because many BMGM avoid public disclosure of their sexual identity and choose to remain 'invisible' (Jaspal 2012). Furthermore, our research has usually been concerned with those BMGM who are not affiliated to gay affirmative 
religious support group networks (e.g. $\operatorname{Imaan}^{3}$ ). Our work suggests that the implications for identity and social relations seem to be somewhat different among BMGM who are not affiliated to these networks. In order to gain access to this population, we have habitually employed a snowball sampling strategy with initial participants recruited from within our own social networks. This has facilitated the construction of a convenience sample. In total, 47 BMGM between the ages of 18 and 28 have participated in our interview studies.

\section{Analysis and procedure}

The data were analysed using qualitative thematic analysis, which has been described as 'a method for identifying, analysing and reporting patterns (themes) within data' (Braun and Clarke 2006: 78). The study aimed to capture participants' attempts to make sense of their personal and social worlds, with particular foci upon identity threat and emotion.

Consequently, the analysis adopts a realist, epistemological approach in that participants' talk is viewed as a fairly reliable reflection of their cognitions. Interviews were digitally recorded and transcribed verbatim. It is noteworthy that data from the four interview studies have been re-analysed for the purpose of the present chapter. In the quotations from participants, an ellipsis indicates where material has been excised; and other material within square brackets is clarificatory.

\section{Analysis}

\section{Identity dissonance and feelings of shame and guilt}

The perception of dissonance between religious and sexual identities among BMGM can threaten the psychological coherence principle of identity. In reflecting upon the emotional implications of this discordance, participants have manifested both shame and guilt:

It's [homosexuality] against Islam, it's wrong, a sin and I know I'm probably going to go to hell...I feel so ashamed of myself. I'm doing wrong and I know I shouldn't be. I'm letting myself down, it's against God, my religion, my community...it makes me feel really just bad inside, like bad about myself (Asif)

There is a clear sense of shame manifested in Asif's account. This arises from the perceived sinfulness of homosexuality, which could allegedly result in the wrongdoer's condemnation to hell. The perception that being gay equals 'doing wrong' in the eyes of 'God, my religion, [and] my community' seems to induce feelings of shame and guilt. Crucially, this negative, discriminatory representation from religious sources engenders the perception that Muslim and gay identities are incompatible, threatening psychological coherence. Like Asif, participants seem to experience unease at the intrapsychic level, as their private conscience dictates that being gay is wrong. This can induce feelings of guilt, which is reflected in the

\footnotetext{
${ }^{3}$ Al-Fatiha UK, which was established in 1999, was the first UK-based support group organisation for gay, lesbian and bisexual Muslims. In 2004, the organisation changed its name to Imaan (the Arabic word for 'faith').
} 
participant's sense of inadequacy and regret. Furthermore, there is a clear sense of social wrongdoing, which is tied to the perception of public disapproval. This reflects the emotion of shame (Broucek 1991). Collectively, these emotions may be conducive to a negative selfconception.

There is an entwined sense of shame and guilt, given the intermeshed social and psychological consequences of being gay and Muslim:

It feels pretty painful to be honest with you because it goes against everything I believe in...I just close my eyes sometimes and keep them closed, slap myself, I don't feel like opening them when I think about it...Sometimes I can't like, I can't face the Imam at the mosque because it's the shame of it, even though he don't know that like what I've done. (Faisal)

On the one hand, being gay is perceived as contradicting one's psychological worldview and, on the other, it is regarded as an example of social misconduct. The discrepancy between the 'ideal' self and the self which encompasses the seemingly incompatible Muslim and gay identities seems to jeopardise psychological coherence. The perceived incompatibility of these identities is clearly grounded within negative social representations of homosexuality disseminated by religious sources (Duran 1993). Faisal's account highlights the emotional consequences of perceiving dissonance between sexual and religious identities. His desire to 'close my eyes sometimes and keep them closed, slap myself' seems to highlight feelings of guilt, since his private conscience induces both symbolic self-withdrawal and selfflagellation. Moreover, despite Faisal's acknowledgement that his gay identity is unknown to significant others, such as the imam of his local mosque, he nonetheless feels unable to 'face' this human representative of his religious identity. The entwined emotions of guilt and shame may induce an isolationist strategy, whereby the individual decides to avoid facing others who render salient threatening stimuli (i.e. the incompatibility of one's identities) (Breakwell 1986). Indeed, religious figures such as the imam may be said to render salient threatening stimuli; in our research BMGM have attributed the illegality of homosexuality to Koranic interpretations offered by religious scholars (Jaspal and Cinnirella 2010). It is noteworthy that the participant himself attributes this strategy of self-withdrawal to feelings of shame which ensue from the co-existence of his Muslim and gay identities.

The negative emotion of shame due to perceived incompatibility seems to result from individuals' private conscience:

I just prefer to forget about it, like switch off, that helps...I just don't think about it when I'm with a guy, I just switch off, don't think about being a Muslim. I know that sounds really bad but how can I think of that if, if Islam says you kill a gay? I know I'll get my punishment afterwards, believe me, I do know it... When I look back, I feel even more shit about myself than I did before (Imran)

The emotion of guilt is manifested by Imran's strong belief that his sexual 'wrongdoing' will be punished in the afterlife; there are clear feelings of culpability and inadequacy at work 
here. In addition to the negative outcomes for psychological coherence, religious homophobia, of which most participants expressed acute awareness, can impede a positive self-conception, resulting in decreased self-esteem. It is possible that among BMGM, threats to these principles, in particular, induce the negative emotions of guilt and shame.

In our research, BMGM have typically manifested intrapsychic strategies for attenuating the emotions of shame and guilt. In order to cope with these negative emotions, Imran seems to engage in the intrapsychic strategy of denial by simply suppressing knowledge of any dissonance between his religious and sexual identities. This can be achieved by attenuating Muslim identity in those social contexts in which gay identity may plausibly be regarded as 'core' and in which conflict between Muslim and gay identities may occur. Imran describes a social context in which his gay identity seems to be 'core', namely during romantic/ sexual encounters with other gay men. The psychological practice of attenuating one identity in favour of another in particular social contexts has been referred to as compartmentalisation (Breakwell 1986). Although there is evidence of compartmentalisation among some BMGM (see also Yip 2004a), religious identity tends to be construed as pervasively 'core' (and sometimes as a 'meaning system') by many Muslims (Norcliffe 1999). This may decrease the efficacy of compartmentalisation as a coping strategy, as suggested by Imran's acknowledgement that compartmentalising Muslim and gay identities 'sounds really bad'. The coping strategy itself seems to be potentially threatening (Jaspal \& Cinnirella 2010). Nonetheless, the strategies of denial and compartmentalisation, though potentially problematic given the 'core-ness' of Muslim identity, may be construed as necessary when thinking about the perceived incompatibilities of Islam and homosexuality.

\section{Ingroup norms, God's norms and the experience of fear}

Religious homophobia encourages the perception that Islam and homosexuality are incompatible and irreconcilable, while cultural homophobia indicates the incongruity of membership in the ethno-cultural group and self-identification as gay. In both cases, homosexuality is represented as a contravention of ingroup norms. This can have adverse outcomes for the belonging principle of identity, since being gay can itself hinder acceptance and inclusion in the religious and ethno-cultural groups. In our studies, BMGM have consistently manifested fear as an emotional response to public exposure of their nonnormative ingroup behaviour:

I live my life in fear, I'm scared, 'cause if my brothers found out, they'd kill me, serious...trust me, you don't know them. The topic has come up and they threatened me...My mum caught me watching a gay channel and like they don't chat about it no more but my brothers threatened to kill me...It's 'cause it's wrong in Islam so it's like saying 'I ain't a Muslim' and it's like an honour thing too really like how would my family show their face in the community or go to Pakistan? (Omar)

Omar construes homosexuality as contravening the norms of both his religious and ethnocultural ingroups. According to Omar, homosexuality is stigmatised because, on the one 
hand, homosexual practice equates to apostasy, that is, the rejection of Islamic faith (Rahman 2006). This simile suggests that being gay radically impedes a sense of belonging within the religious group. On the other hand, it jeopardises the ethno-cultural construct of honour. Nonconforming individuals may be seen as threatening the integrity and social position of the family as a whole (Yip 2004b). Indeed, Omar suggests that a gay son could involuntarily cause ostracisation of the entire family. Given that religion and ethnic culture can constitute primary sources of belonging among many BMGM (Jaspal 2012), this principle may be particularly vulnerable to threat.

The perception that homosexuality constitutes a severe contravention of norms associated with these group memberships can accentuate fear of sexual disclosure. More generally, religious and cultural homophobia renders 'coming out' a threatening prospect. Omar was not alone in highlighting the possibility that 'coming out' as gay could result in psychological and even physical abuse from members of his family (Jaspal and Siraj 2011). He was convinced that his brothers might kill him for being gay, a hypothesis which was grounded in previous experiences of discussing homosexuality with his family. Given the enforced 'silencing' of homosexuality within the family and cultural ingroup more generally (Murray 1997), fear of exposure and open allusion to his gay identity continue to induce fear.

Religious homophobia encourages the notion that God will punish individuals who engage in homosexual acts (Duran 1993). Like 'coming out', this too can induce the emotional experience of fear, as outlined in participants' reported experiences in 'gay space':

I sat down [in Heaven, a gay nightclub in London] and I kept thinking the roof was going to fall in any minute and that we'd all die there and then...I knew it was a bad place with bad stuff going on around me. I hated that night. (Aziz)

The perceived sinfulness of homosexuality from the perspective of his religious identity seems to induce a fear of divine retribution (Jaspal and Cinnirella 2010). Aziz regards his participation in 'gay space' as a contravention of the social and sexual norms associated with his religious identity. This engenders fear of an act of God to 'punish' him and other gay men in what is described as 'a bad place'. Given the centrality of Muslim identity, Aziz employs this identity as the interpretive lens through which gay space is evaluated: 'I knew it was a bad place with bad stuff going on around me'. More generally, the potent emotional experience seems to induce a highly negative evaluation of gay space. This is unfortunate, given that gay space may constitute an important means of constructing 'social capital' among BMGM (Jaspal and Cinnirella 2012). In some contexts, the emotion of fear may be alleviated by ensuring that one's sexual identity remain secret and socially denied, that is, 'silenced' as exemplified above. However, the fear manifested in Aziz's account seems to be less easily escapable. The fearful stimulus is located at the intrapsychic, rather than social, level. He perceives his behaviour to be in conflict with the norms established by God's word, which therefore concerns his spiritual relationship with God, rather than a social relationship with the institution of religion (e.g. Berger et al. 2008). Thus, 'social' denial of one's gay identity is unlikely to constitute an adequate coping strategy. 
In our work, this 'intrapsychic' fear of contravening God's norms seems to impede the development of personal and sexual relationships with other men:

Mohammed: I don't meet that many guys off the internet but if I do I just regret it afterwards... 'cause it's like, it feels wrong afterwards and I just get scared, like really worried about what's going to happen to me...I can lie to my parents and that but God knows what I'm doing.

Interviewer: Has it affected your relationships with, I mean, how has it sort of affected your relationships with guys?

Mohammed: Just silly things like after being with a guy, he's like talking to me and I'm coming out with my own thing like making some excuse to leave or just telling him I don't do it much. It's stupid I know but the strong feelings just take, come over me.

Mohammed notes that, although he can conceal his homosexuality and feign heterosexuality in social contexts, 'God knows what I'm doing'. It seems that the emotional experience of fear can seriously impede the development of positive interpersonal relations, and thereby jeopardise sufficient levels of 'social capital' among some BMGM (Yip 2004a).

Fear of contravening God's norms, as described in relation to the accounts of Aziz and Mohammed, may be alleviated by engaging in the strategy of repentance:

I just go home and I pray, after each one [sexual encounter], each sin, I pray to God and ask for forgiveness...then I feel better because God is a just god. We call him Rahim [merciful]. (Jamal)

The construal of homosexuality as 'wrongdoing' implicitly constructs repentance as the 'appropriate' response. Participants who manifested the emotion of fear when thinking about the implications of being gay for their Muslim identity reported praying and seeking God's forgiveness. This may be regarded in terms of an accessible and effective strategy for alleviating this negative emotional experience, since Islam constructs Allah (God) as merciful towards Muslims (Gould 2008). In fact, Jamal cites one of the ninety-nine Arabic names for God, Rahim, which means 'merciful'.

More generally, both socially and psychologically induced fear (i.e. fear of ostracisation and fear of God, respectively) could be alleviated by hoping for an eventual change in sexual orientation:

It scares me when I think about my future, everything about being gay is scary...I'll be alone at the end, I know it...Being gay goes against Islam completely, I know, but I try to resist it. I want to get married some day. (Mohsan) 
For many BMGM, the prospect of marriage can constitute a short-term strategy for coping with their fear-inducing gay identity, since psychologically it provides scope for change which can remove the source of fear (Jaspal 2012). Crucially, this change is consistent with and respectful of the social and sexual norms associated with their religious and cultural ingroups, which are generally averse to homosexuality.

\section{Managing interpersonal relations and anger}

BMGM generally attach phenomenological importance to the family (Yip 2004b). The family and religious and ethno-cultural ingroups are said to constitute primary sources of belonging, acceptance and inclusion among BMGM (Jaspal 2012). However, disclosure of one's gay identity may disrupt the much-valued interpersonal relations within the family unit. This may be attributed to both religious and cultural forms of homophobia, since homosexuality is socially represented as contradicting the Islamic worldview as well as key norms and customs associated with the ethno-cultural ingroup (e.g. [arranged] marriage).

As outlined in relation to Mohsan's account, some BMGM outline their wish that they were not gay and their desire to change their sexual orientation. This change may be regarded as essential for safeguarding relationships with significant others (Jaspal 2012). However, the perceived inability to change can induce feelings of helplessness and anger:

I just hate feeling so damn helpless, I can't change who I am, I know it's the way I was made but who gets that? Innit? My parents aren't gonna get that when they kill me and that's true my family will kill me...I feel so fucking mad at myself, like I'm going crazy or something...I've smashed my hand in the mirror 'cause I get so angry at myself and my life. Why me?... Why can't I change this? (Ahmad)

Given that Ahmed fears that the disclosure of his sexual identity could result in physical abuse or a threat to his life, his inability to change his sexual orientation is all the more threatening for identity. It does not allow him to shape his future 'self' in accordance with his constructed 'ideal' self. Given that human beings usually have agency in constructing identity (Breakwell 1986), this inability can inhibit feelings of control and competence, which are essential for the self-efficacy principle. This seems to induce the emotional experience of anger, as he feels 'mad' at himself and as if he is 'going crazy or something'. This may constitute a response to this helplessness and perceived inadequacy. Like several other participants, Ahmad described behaviours typically associated with the intense emotion of anger, such as damaging objects and self-harm (Deffenbacher 1992). It is noteworthy that decreased self-efficacy is not universally threatening for BMGM, some of whom actively attenuate self-efficacy in order to reconcile their religious and sexual identities (Jaspal and Cinnirella 2010). However, in this context, the aim seems to be self-construal as a 'good' Muslim, rather than a gay Muslim, as the two identities are perceived as incompatible. Therefore, the self-efficacy principle (that is, the competence to change) is salient.

Our research has typically focused upon BMGM who have not publicly disclosed their sexual identities. However, those individuals who did contemplate 'coming out' tended 
to express anger at members of their family and their ethno-religious ingroup due to perceived homophobia:

My family is ruining my life and it pisses me off...I'm gay and it's the way I am, yeah, it's the way I was born and I can't change it...My folks don't accept it and they have all these stupid expectations. Drives me mad...It just shakes me up totally and I feel like shouting it out so loud so everyone can hear it but once it's said, it's said and there's no turning back, no more pretending... denying what's in your face. (Sajid)

Participants who have developed interpersonal relations with other gay men in 'gay space' seem to manifest greater willingness to explore these alternative social networks in order to derive feelings of belonging (Jaspal 2012). As these alternative networks are explored, BMGM may manifest feelings of anger towards individuals within their ethno-religious circles, given that homophobic discrimination is increasingly perceived to be unreasonable. Crucially, BMGM may feel more empowered to criticise the social groups with which they identify, because they have access to alternative social groups (Breakwell 1986).

Participants may begin to regard homophobic discrimination from these groups as unjust as they construe their gay identity in essentialist terms as a primordial, innate sexual orientation. The essentialisation of gay identity seems to induce the perception that their parents' expectations regarding sexuality and social life are 'stupid' and unreasonable. While 'closeted' BMGM who do not yet entertain the prospect of 'coming out' may themselves manifest the view that being gay is 'wrong', 'sinful' or a 'chosen' lifestyle (Jaspal and Cinnirella 2010), those who do contemplate 'coming out' seem to perceive this view as a clear example of (unreasonable) homophobic discrimination. Crucially, at this stage of sexual identity development, the perceived unjustness of homophobic discrimination may cause the emotional experience of anger. Sajid states that it 'drives me mad' and 'shakes me up', inducing the desire to 'shout it out loud'. In this case, it seems that public disclosure of his gay identity is construed as a means of alleviating the negative emotion of anger. However, there is a simultaneous recognition that this strategy could have potentially irreversible consequences; it could undermine the social denial strategy, which is said to constitute an important social response to homosexuality within ethno-religious circles (Murray 1997).

\section{Concluding remarks}

This chapter makes a novel contribution to research and theory by exploring how homophobic ideas and representations associated with religious and cultural group memberships may affect the self-concept and induce particular emotional experiences among BMGM. Furthermore, there was a concern with the socio-psychological strategies manifested in order to cope with such religious and cultural homophobia.

Throughout our studies, participants have consistently manifested the negative emotions of shame, guilt, fear and anger when reflecting upon being Muslim and gay. These emotional experiences can plausibly be attributed to BMGM's awareness of and exposure to both religious and cultural homophobia. As an example of such homophobia, in January 2012 
Derby Crown Court found five Muslim men of Pakistani descent guilty of distributing in the City of Derby anti-gay leaflets calling for the death penalty for gay people (Britten 2012). This incident and reported experiences of discrimination, both implicit and explicit, within religious and cultural settings collectively exemplify the religious and cultural homophobia surrounding many BMGM (Siraj 2009). This can induce both identity threat and negative emotions.

There is some evidence that identity threat can result in negative emotional experiences (Murtagh 2009). Our work has shown that BMGM can perceive dissonance between their religious and sexual identities, which can result in threats to the psychological coherence principle of identity (Jaspal and Cinnirella 2010). Moreover, the general 'coreness' of Muslim identity vis-à-vis gay identity can mean that the negative evaluations of homosexuality according to Islamic ideology are accepted and internalised by BMGM themselves. This may result in threats to self-esteem. This affects the intrapsychic level of cognition, since it shapes how BMGM think about being Muslim and gay, as well as the social level in that it may influence how BMGM relate to others. Challenges to the intrapsychic level seem to be associated with the emotional experience of guilt, since there is an intrapsychic perception of wrongdoing which primarily affects one's private conscience (Tangney and Fischer 1995). Accordingly, participants in our studies have typically reported engaging in intrapsychic strategies for coping, such as denial and compartmentalisation. However, the efficacy of these strategies is limited given that they are transient and themselves fraught with secondary difficulties. For instance, the 'core' position of Muslim identity within the self-concept among many BMGM can undermine the viability of the compartmentalisation strategy (Jaspal and Cinnirella 2010). Possibly due to the imminent failure of deflection strategies, such as denial and compartmentalisation, in the long run, some participants worryingly reported engaging in self-flagellation and self-harm in order to alleviate their feelings of guilt. Conversely, the perception of social wrongdoing seems to be associated with the emotional experience of shame due to the perceived possibility of selfexposure to disapproval from others (Broucek 1991). Accordingly, BMGM may engage in interpersonal strategies for coping with negative emotions with social antecedents, such as self-withdrawal from religious circles and general self-isolation.

BMGM may express the belief that their gay identity contravenes key norms and values associated with their religious and cultural group memberships. The anticipated threat to acceptance and inclusion (belonging) in these social groups, which essentially denigrate, undermine and stigmatise gay identity, can induce fear. Furthermore, participants reported their intense fear that their gay identity could be disclosed to members of their religious and cultural ingroups, possibly resulting in ostracisation from the groups or even physical harm (Jaspal and Siraj 2011). In this case, fear has a social antecedent and thus social denial (or 'silencing') of gay identity may be regarded as an appropriate coping strategy. Moreover, the emotion of fear could ensue from participants' perception that their gay identity constitutes a violation of God's norms, potentially resulting in divine punishment. This fear is described as intrapsychic given that it ensues from the individual's spiritual connection with an omnipresent God. Accordingly, social denial seems to constitute a less effective strategy for coping, given that participants feel that they cannot conceal their gay identity from God, as 
they habitually do from members of their religious and cultural ingroups. Consequently, BMGM may engage in divine repentance in order to alleviate their fear.

Due to religious and cultural homophobia, the assimilation and accommodation of a gay identity in the self-concept can be challenging and conducive to negative emotions. Throughout our studies, we have observed that in order to cope BMGM may construct their gay identity in terms of a mutable behaviour, rather than as an identity, which is consistent with their hope that they may be able to 'become straight'. This may alleviate negative emotions. However, for BMGM who are hopeful that they will be able to change their sexual orientation, the perceived inability (in real terms) to become straight can itself induce anger. This seems to be associated with perceived helplessness, inadequacy of the self and decreased self-efficacy, particularly as individuals recognise that they may have less control and competence over their sexual orientation than originally believed (cf. Jaspal and Cinnirella 2010). However, there is some evidence that BMGM may begin to contemplate 'coming out' as gay in the long run, provided that they have developed alternative social networks which can provide feelings of acceptance, inclusion and belonging. The perception of an alternative source of belonging can facilitate the assimilation and accommodation of their gay identity within the self-concept, encouraging BMGM to abandon the hope of changing their sexual orientation. At this stage of sexual identity development, some BMGM may begin to manifest anger towards members of their religious and cultural ingroups, as their respective positions on homosexuality are increasingly regarded as being unreasonable and even 'stupid'.

This chapter echoes an over-arching theme in the literature that being Muslim and gay can induce 'hyper-threats' to identity. This may be attributed to the prevalence of religious and cultural homophobia in the lives of many BMGM. This can adversely affect (i) psychological coherence in relation to Muslim and gay identities; (ii) self-esteem due to the negative evaluation of gay identity in religious and cultural group contexts; and (iii) belonging in the family unit and in the religious and cultural groups. Threats to these principles are associated with the negative emotional experiences of guilt, shame, fear and anger. BMGM may cope with identity threat and the experience of negative emotions by deploying intrapsychic and social coping strategies, including denial, divine repentance, selfharm, social 'silencing' of gay identity and self-isolation. Our research suggests that, in addition to identity threat, emotionality constitutes an important dimension of the interface of religion and sexuality. It is hoped that this chapter will stimulate further investigation from additional theoretical, methodological and disciplinary approaches.

\section{Acknowledgements}

The author would like to thank the editors for their detailed and constructive comments on an earlier version of this chapter.

\section{References}

Averill, J.R. 1982. Anger and Aggression: An Essay on Emotion. New York: Springer. Berger, P., Davie, G. and Fokas, E. 2008. Religious America, Secular Europe? A Theme and 
Variations. Aldershot: Ashgate.

Bhugra, D. 1997. Coming out by South Asian gay men in the United Kingdom. Archives of Sexual Behavior, 26(5), 547-557.

Braun, V. and Clarke, V. 2006. Using thematic analysis in psychology. Qualitative Research in Psychology, 3(2), 77-101.

Breakwell, G.M. 1986. Coping with Threatened Identities. London: Methuen.

Broucek, F.J. 1991. Shame and the Self. New York: Guilford.

Britten, N. 2012. Muslims posted 'nasty and frightening' anti-gay leaflets demanding homosexuals 'turn or burn'. The Daily Telegraph, $18^{\text {th }}$ January 2012. Available at: http://www.telegraph.co.uk/news/uknews/law-and-order/9004998/Muslims-postednasty-and-frightening-anti-gay-leaflets-demanding-homosexuals-turn-or-burn.html [accessed: 18 January 2012]

Carlson, D. 1997. Gayness, multicultural education and community, in Beyond Black and White, edited by M. Seller and L. Weis. Albany, NY: State University of New York Press.

Deffenbacher, J.L. 1992. Trait anger: Theory, findings and implications, in Advanced Personality Assessment, edited by C.D. Spielberger and J.N. Butcher. Hillsdale, New Jersey: Lawrence Erlbaum, 177-201.

Duran, K. 1993. Homosexuality in Islam, in Homosexuality and World Religions, edited by A. Swidler. Harrisburg, PA: Trinity Press, 181-198.

Eatough, V. and Smith, J. 2006. 'I was like a wild wild person': Understanding feelings of anger using interpretative phenomenological analysis. British Journal of Psychology, 97(4), 483-498.

Gould, M. 2008. Islam, the law and the sovereignity of God. Policy Review, 149. Available at: http://www.hoover.org/publications/policy-review/article/5693 [accessed: 22 January 2012].

Haqqani, H. 2004. The role of Islam in Pakistan's future. The Washington Quarterly, 28(1), 85-96.

Harré, R. and Finlay-Jones, R. 1986. Emotion talk across time, in The Social Construction of Emotions, edited by R. Harré. Oxford, England: Basil Blackwell, 220-233.

Heaphy, B., Weeks J. and Donovan, C. 1998. That's like my life: Researching stories of non-heterosexual relationships. Sexualities, 1(4), 453-70.

Herek, G.M. (2004). Beyond "homophobia": Thinking about sexual prejudice and stigma in the twenty-first century. Sexuality Research and Social Policy, 1(2), 6-24.

Hudson, W.W. and Ricketts, W. A. 1980. A strategy for the measurement of homophobia. Journal of Homosexuality, 5(4), 357-372.

Jamal, A. 2001. The story of Lot and the Quran's perceptions of the morality of same-sex sexuality. Journal of Homosexuality, 41(1), 1-88.

Jaspal, R. 2012. Homosexuality, religion and ethnicity among British South Asian gay men: Identity and social representation. Paper presented at the Youth, Gender and Sexuality: Contemporary Debates Conference, University of Nottingham, 25 January 2012. 
Jaspal, R. and Cinnirella, M. 2010. Coping with potentially incompatible identities: Accounts of religious, ethnic and sexual identities from British Pakistani men who identify as Muslim and gay. British Journal of Social Psychology, 49(4), 849-870.

Jaspal, R. and Cinnirella, M. 2012. Identity processes, threat and interpersonal relations: Accounts from British Muslim gay men. Journal of Homosexuality, 59(2), 215-40.

Jaspal, R. and Siraj, A. 2011. Perceptions of 'coming out' among British Muslim gay men. Psychology and Sexuality, 2(3), 183-197.

Khan, B. 1997. Not-so-gay life in Pakistan in the 1980s and 1990s, in Islamic Homosexualites: Culture, History, and Literature, edited by S.O. Murray and W. Roscoe. New York: New York University Press, 275-296.

Kugle, S.S.A. 2010. Homosexuality in Islam: Critical Reflection on Gay, Lesbian, and Transgender Muslims. Oxford: Oneworld Publications.

Markus, H.R. and Kitayama, S. 1991. Culture and the self: Implications for cognition, emotion, and motivation. Psychological Review, 98(2), 224-253.

Massey, D. 2002. Emotion and the history of human society. American Sociological Review 64, 1-29.

Modood, T., Berthoud, R., Lakey, J., Nazroo, J., Smith, P., Virdee, S. and Beishon, S. 1997. Ethnic Minorities in Britain: Diversity and Disadvantage. London: Policy Studies Institute.

Murray, S.O. 1997. The will not to know: Islamic accommodations of male homosexuality, in Islamic Homosexualities, edited by S.O. Murray and W. Roscoe. New York: New York University Press, 14-54.

Murtagh, N. 2009. Voluntary Occupation Change: A Social Psychological Investigation of Experience And Process. Unpublished PhD thesis, University of Surrey, UK.

Norcliffe, D. 1999. Islam: Faith and Practice. Brighton: Sussex Academic Press.

Öhman, A. 2000. Fear and anxiety: Evolutionary, cognitive, and clinical perspectives, in Handbook of Emotions, edited by M. Lewis and J.M. Haviland-Jones. New York: The Guilford Press, 573-593.

Parrot, W. R. 2004. The nature of emotion, in Emotion and Motivation, edited by M.B. Brewer and M. Hewstone. Malden, MA: Blackwell, 5-20.

Rahman, S.A. 2006. The Punishment of Apostasy in Islam. Lahore: The Other Press Sdn Bhd. Rosario, M., Schrimshaw, E. W., Hunter, J. and Gwadz, M. 2002. Gay-related stress and emotional distress among gay, lesbian and bisexual youths: A longitudinal examination. Journal of Consulting and Clinical Psychology, 70(4), 967-975.

Shaw, A. 2000. Kinship and Continuity: Pakistani Families in Britain. Amsterdam: Harwood Academic Publishers.

Siraj, A. 2009. The construction of the homosexual "Other" by British Muslim heterosexuals. Contemporary Islam, 3(1), 41-57.

Tangney, J. P. and Fischer, K. W. (eds.). 1995. Self-conscious Emotions: The Psychology of Shame, Guilt, Embarrassment and Pride. New York: Guilford Press.

Turner J.H. 1999. Toward a general sociological theory of emotions. Journal for the Theory of Social Behaviour, 29(2), 133-62 
Weinberg, G. 1972. Society and the Healthy Homosexual. Garden City, New York: Doubleday.

Yip, A.K.T. 2004. Embracing Allah and sexuality? South Asian non-heterosexual Muslims in Britain, in South Asians in the Diaspora, edited by K.A. Jacobsen and P.P. Kumar. Leiden: Brill, 294-310.

Yip, A.K.T. 2004. Negotiating space with family and kin in identity construction: the narratives of British non-heterosexual Muslims. The Sociological Review, 52(3), 336350.

Yip, A.K.T. 2005. Queering religious texts: An exploration of British non-heterosexual Christians' and Muslims' strategy of constructing sexuality-affirming hermeneutics. Sociology, 39(1): 47-65

Yip, A.K.T. 2007. Sexual orientation discrimination in religious communities, in Sexual Orientation Discrimination: An International Perspective, edited by M.V.L. Badgett and J. Frank. London: Routledge, 209-244.

Yip, A.K.T. 2012. Homophobia and ethnic minority communities in the United Kingdom, in Confronting Homophobia in Europe, edited by L. Trappolin, A. Gasparini and R. Wintemute. Oxford: Hart Publishing, 107-130. 